\title{
Correction: Yu, L., et al. Evaluation of Moist Static Energy in a Simulated Tropical Cyclone. Atmosphere 2019, 10, 319/doi:10.3390/atmos10060319
}

\author{
Lijun $\mathrm{Yu}^{1}$, Shuhui $\mathrm{Wu}^{2}$ and Zhanhong Ma ${ }^{1, *}$ \\ 1 College of Meteorology and Oceanography, National University of Defense Technology, \\ Nanjing 211101, China; lijunyu198208@163.com \\ 2 Department of Finance, Sanjiang University, Nanjing 210012, China; shuhuiwu0205@163.com \\ * Correspondence: hongzhanm@163.com
}

Received: 24 July 2020; Accepted: 30 July 2020; Published: 1 August 2020

The authors wish to make the following corrections to this paper:

1. Change in Model Setup (Section 2.1)

2. Changes in Overview of Storm Evolution (Section 2.3)

3. Changes in captions of Figures 1-3

The authors would like to apologize for any inconvenience caused to the readers by these changes.

The authors unintentionally used the same model configuration as Ma et al. (2015) [1]. This was caused by a wrong use of namelist.input in WRF. As a consequence, the model output data are the same as in Ma et al. (2015) [1], but at different time intervals. These errors do not affect the main conclusions and findings of the paper. The authors wish to make the following corrections to the paper:

1. Change in Model Setup (Section 2.1)

On page 2, line 45: the sentence "The outer domain utilizes the Kain-Fritsch scheme (Kain 2004) to parameterize the cumulus processes, while no cumulus parameterization is used in the two inner meshes" should be "The cumulus processes are represented explicitly and no parameterization scheme has been used".

2. Change in Overview of Storm Evolution (Section 2.3)

Since the model output data are the same as Ma et al. (2015) [1] with different time intervals, the introduction of basic information about the simulated storm, shown in Figures 1 and 2, does not provide much new knowledge, especially the intensity evolution.

3. Changes in captions of Figures 1-3

The caption of Figure 1 should be "Time evolution of (a) minimum sea level pressure (hPa) and (b) maximum azimuthal mean wind speed at lowest model level $\left(\mathrm{m} \mathrm{s}^{-1}\right)$. The figure incorporates the same information as Figure 1a in Ma et al. (2015) [1]".

The caption of Figure 2 should be "Height-radius cross-sections of azimuthal mean (a) tangential winds $\left(\mathrm{m} \mathrm{s}^{-1}\right),(\mathrm{b})$ radial winds $\left(\mathrm{m} \mathrm{s}^{-1}\right)$, (c) vertical winds $\left(\mathrm{m} \mathrm{s}^{-1}\right)$, and (d) potential temperature anomalies (K) averaged between $108 \mathrm{~h}$ and $120 \mathrm{~h}$. The panels (a)-(c) incorporate the information in Figure $1 \mathrm{~b}$ of Ma et al. (2015) [1], but are vertically extended to $20 \mathrm{~km}$ since an integration from model bottom to model top $(20 \mathrm{~km})$ is used in the following budget analysis".

The caption of Figure 3 should be "As in Figure 2, but for (a) MSE normalized by $c_{p}(\mathrm{~K})$, (b) equivalent potential temperature (K) defined by Bolton (1980), (c) equivalent potential temperature (K) defined by Rotunno and Emanuel (1987), and (d) equivalent potential temperature difference (K) between definitions of Bolton (1980) and Rotunno and Emanuel (1987). The panels (a)-(b) incorporate the information in Figure 2 of Ma et al. (2015) [1], but are vertically extended to $20 \mathrm{~km}$ since an integration from model bottom to model top $(\sim 20 \mathrm{~km})$ is used in the following budget analysis". 
These changes have no material impact on the conclusions of our paper. We apologize for any inconvenience caused to the readers.

\section{Reference}

1. Ma, Z.; Fei, J.; Huang, X.; Cheng, X. A potential problem of the applications of moist static energy in tropical cyclone studies. J. Atmos. Sci. 2015, 72, 3009-3019. [CrossRef]

(c)

(C) 2020 by the authors. Licensee MDPI, Basel, Switzerland. This article is an open access article distributed under the terms and conditions of the Creative Commons Attribution (CC BY) license (http://creativecommons.org/licenses/by/4.0/). 